\title{
The gold standard for the treatment of uncomplicated adult ureteropelvic junction obstruction
}

\author{
Patrick Luke, MD
}

See related article on page 388

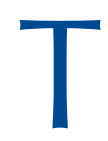

he members of the highly experienced laparoscopy group from McMaster have demonstrated that their excellent results with laparoscopic pyeloplasty continue to be maintained with longer follow-up and greater numbers. ${ }^{1}$ Since Kavoussi's group demonstrated laparoscopic pyeloplasty results in 100 patients to be equivalent to open pyeloplasty success, ${ }^{2}$ several experienced laparoscopic groups have also shown success rates of over $90 \%$ with minimal narcotic requirements, convalescent times and morbidity, compared with open pyeloplasty procedures..$^{3-5}$ In contrast to the disappointing long-term results of endopyelotomy, ${ }^{6}$ the success of the Anderson-Hynes laparoscopic pyeloplasty remains robust, ${ }^{7,8}$ and there is no theoretic reason to believe that long-term results should be inferior to those of open pyeloplasty.

Some experts have suggested that laparoscopic pyeloplasty is "evolving" to become the gold standard in the repair of symptomatic ureteropelvic junction obstruction (UPJO) in adults. Laparoscopic pyeloplasty has reproducibly excellent short- and long-term results and minimal morbidity, compared with open pyeloplasty, and it can be argued that laparoscopic pyeloplasty should indeed be the current gold standard for the treatment of uncomplicated adult UPJO. However, it is considered a moderately to highly complex laparoscopic procedure ${ }^{9}$ and cannot be offered in most community-based urologic centres, which evaluate a low volume of patients with UPJO. Fortunately, there are experienced laparoscopic surgeons at each Canadian academic centre who can offer laparoscopic pyeloplasty. If surgeons adhere to the basic principles of UPJO repair, there is no reason to believe that success rates of the Anderson-Hynes laparoscopic pyeloplasty should be inferior to those of open repair. The volume of laparoscopic pyeloplasty at these centres should reflect operative times and complication rates. In the case of the highly experienced McMaster group, acceptable complication rates and operative times of just over 3 hours have been demonstrated.

In Canada, several centres have acquired or are in the process of acquiring surgical robots. These robots have been shown to improve surgical ergonomics and efficacy when compared with laparoscopy. ${ }^{10}$ In fact, it has been demonstrated that the surgical robot is capable of flattening the learning curve and allowing laparoscopically naive surgeons to embark on "advanced" laparoscopic procedures that could not otherwise have been achieved without robotics. ${ }^{11-13}$ Although the most experienced surgeons have shown that robotics have not improved operative times and results, owing to docking and instrument exchange times, ${ }^{14}$ there are several studies from centres with less experience that have shown equivalent surgical results and significant reduction of surgical times with the use of the robot. ${ }^{15}$ Our centre's long-term results in 55 patients and our surgical times of under 3 hours support this claim. ${ }^{16,17}$ In summary, if patients have access to experienced laparoscopic surgeons or moderately experienced surgeons with advanced (albeit expensive) technology, I believe that the laparoscopic pyeloplasty should be offered as the current gold standard for the repair of uncomplicated adult UPJO.

Associate Professor of Surgery, University of Western Ontario, London Health Sciences Centre, University Hospital, London, Ont.

Competing interests: None declared.

\section{References}

1. Hussain A, Whelan P, Piercey K, et al. McMaster experience with laparoscopic pyeloplasty. Can J Urol 2004; 11:2299-302.

2. Jarrett TW, Chan DY, Charambura TC, et al. Laparoscopic pyeloplasty: the first 100 cases. J Urol 2002;167:1253-6.

3. Calvert RC, Morsy MM, Zelhof B, et al. Comparison of laparoscopic and open pyeloplasty in 100 patients with pelvi-ureteric junction obstruction. Surg Endosc 2008;22:411-4

4. Klingler HC, Remzi M, Janetschek $G$, et al. Comparison of open versus laparoscopic pyeloplasty techniques in treatment of uretero-pelvic junction obstruction. Eur Urol 2003;44:340-5.

5. Soulié $M$, Thoulouzan $M$, Seguin $P$, et al. Retroperitoneal laparoscopic versus open pyeloplasty with a minimal incision: comparison of two surgical approaches. Urology 2001;57:443-7.

6. Knudsen BE, Cook AJ, Watterson JD, et al. Percutaneous antegrade endopyelotomy: long-term results from one institution. Urology 2004;63:230-4.

7. Dimarco DS, Gettman MT, McGee SM, et al. Long-term success of antegrade endopyelotomy compared with pyeloplasty at a single institution. J Endourol 2006;20:707-12.

8. Madi R, Roberts WW, Wolf JS Jr. Late failures after laparoscopic pyeloplasty. Urology 2008;71:677-80.

9. Kaouk JH, Gill IS. Laparoscopic reconstructive urology. J Urol 2003;170: 1070-8.

10. Nguan C, Girvan A, Luke PP. Robotic surgery vs. laparoscopy: a comparison between two robotic systems and laparoscopy. J Robot Surg 2008;1:263-8.

11. Menon M, Shrivastava A, Tewari A, et al. Laparoscopic and robot assisted 
Luke

radical prostatectomy: establishment of a structured program and preliminary analysis of outcomes. J Urol 2002;168:945-9.

12. Ahlering TE, Skarecky D, Lee D, et al. Successful transfer of open surgical skills to a laparoscopic environment using a robotic interface: initial experience with laparoscopic radical prostatectomy. J Urol 2003; 170:1738-41.

13. Chin JL, Luke PP, Pautler SE. Initial experience with robotic-assisted laparoscopic radical prostatectomy in the Canadian health care system. CUAJ 2007;1:97-101.

14. Link RE, Bhayani SB, Kavoussi LR. A prospective comparison of robotic and laparoscopic pyeloplasty. Ann Surg 2006;243:486-91.

15. Gettman MT, Peschel R, Neururer R, et al. A comparison of laparoscopic pyeloplasty performed with the daVinci robotic system versus standard laparoscopic techniques: initial clinical results. Eur Urol 2002;42:453-7.

16. Nguan C, Kwan K, Al Omar M, et al. Robotic pyeloplasty: experience with three robotic plafforms. Can J Urol 2007:14:3571-6.

17. Erdelian P, Caumartin Y, Warren J, et al. Robotic pyeloplasty: long-term follow-up of first Canadian experience. CUAJ 2008;2:309.

Correspondence: Dr. Patrick Luke, Patrick.Luke@hhsc.on.ca

\section{CUA PATIENT INFORMATION BROCHURES}

\section{- For more information on CUA Patient Information Brochures, see page 425.}

\section{- Pour plus d'informations concernant les Brochures nfo-patients de l'AUC,} voir à la page 427.

\section{Urethral \\ Catheter Care}

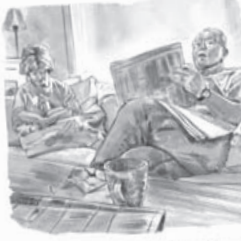

Popper catherer carc wilt mod
and prevent conplications.

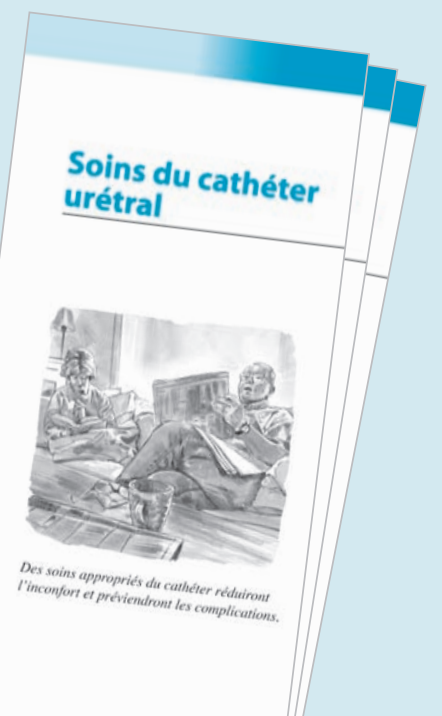

